\title{
A Visit to Baghdad
}

ANDRew C. Smrrh, Consultant Psychiatrist, Greenwich District Hospital, London.

In 1973, Morris Carstairs, writing in the Journal (123, 271-77) on the psychiatric problems of developing countries, made references to Baghdad: the newly completed teaching hospital had very few nurses, and might have been a misguidedly expensive project for a developing country; there were no psychiatric beds in the teaching hospital; the out-patient clinic was primitive; and the students learnt psychiatry only by visits to the unsatisfactory mental hospital.

In 1981, as I found out on a recent visit, much has changed. The country, still with an authoritarian socialist government, is becoming much more prosperous (although now at war with Iran). There is a full social security welfare scheme, with unemployment, sickness and widows' benefits, and pensions.

The medical profession remains very pro-British, which seems to be a continuous tradition dating back to the foundation of the Baghdad Medical School by a British doctor in the 1920s, and kept going by successful postgraduate education in Britain. Of 16 psychiatrists in the civilian health service in the city, 14 trained in this country, and two in Germany. All the teaching of doctors and nurses, every seminar, lecture and discussion in the wards, is in English; the students are issued with the common English textbooks, and even the case notes are kept entirely in English. A visitor therefore feels remarkably at home in educational meetings, despite the crowds in the corridors, and patients in many exotic costumes, including women in black from head to foot. The proportion of women among the medical students is as high as in Britain. British and other foreign journals are read, and the Iraqi Society of Neurologists and Psychiatrists publishes its own journal, Alrazi, twice a year in English and Arabic.

The career of junior doctors proceeds by way of one year as a house officer in a rotating appointment, two years in the Army, one year in a compulsory posting to an underdoctored rural area, and then the direction of the doctor's choice. Most try to come to Britain for postgraduate training, usually on scholarships. National diplomas are planned, but there will be none in psychiatry for some years yet.

The psychiatry in the public hospital service resembles British psychiatry as it might be if it were practised under pressure of large numbers of patients, self-referral to the consultant of choice, and very little family doctoring. Many psychiatrists have to share their working time with neurology. The style of work leans strongly towards brief interviews and physical methods of treatment, and the patients present commonly with tenacious physical complaints of anxious or hysterical origin.

The scale of provision of services in the hospitals (there are no community psychiatric nurses and hardly any social workers) is not so different from ours as might have been expected, for a city population of well over two million, greatly swollen by immigrant workers from neighbouring countries.

The Medical City teaching hospital of Baghdad University has 1,000 beds, of which 45 are for the neuropsychiatric department, admitting 858 patients last year. Of these, 254 were psychiatric admissions (146 depressive syndromes, 46 hysteria, 29 schizophrenia, 21 alcoholism, 7 dementia, 4 puerperal illnesses, 1 acute delirium). The staff for the neuropsychiatric department are five psychiatrists and three trainees. There are many liaison consultations and out-patient clinics. The other medical school, of the Moustansuriyah University, has a purpose-built acute psychiatric unit in the Yarmouk general teaching hospital, with $\mathbf{4 0}$ psychiatric beds, four psychiatrists and two trainees.

A separate small hospital, Ibin Rushid, has 100 acute beds, half of which are used for an alcoholism unit for men. Alcoholism is becoming a problem even in this proudly Moslem country (see Journal, 140, 325-26). The regime is familiar, consisting of drying out and physical investigations followed by educational and psychotherapeutic programmes, including group discussion and occupational activities for several weeks. The hospital has three psychiatrists, four trainees and a rare social worker.

There is a mental hospital, Shamiyah, of 1,200 patients, long-established, and offering a long-stay service for the whole country. It also includes a newly built forensic section of 250 beds and acute wards for 100 patients. There are four psychiatrists and from three to six juniors.

Mental handicap services changed rapidly after responsibility was transferred to the Ministry of Social Welfare under an enthusiastic medical director. Special schools, centres for deaf-mutes, rehabilitation centres, and assessment clinics with doctors, psychologists and social workers, are being developed.

Carstairs doubted the wisdom of aping European services in developing countries-the different conditions require different, locally thought-out and more economical solutions. In this big city the service has indeed grown up based very strongly on hospitals so far. So was our psychiatric service some years ago. 